\title{
Lymph node cellular morphology: comparative study of imprints and cytocentrifuge smears
}

\author{
M W STEVENS, N L FAZZALARI, D J CRISP \\ From the Division of Tissue Pathology, Institute of Medical and Veterinary Science, Adelaide, South Australia
}

SUMmaRY To assess the usefulness of the lymph node imprint technique in quantitating cell types a comparative study using cytocentrifuge smears as:controls was undertaken. The cell dimensions and distribution of cell types were compared in 12 patients with non-Hodgkin's lymphoma (NHL) using semi-automated image analysis. The results show that the imprint procedure introduces selective bias in favour of certain cell types; moreover, certain cell measurements, such as nuclear shape, are easier to see on cytocentrifuge smears. The imprint technique compares unfavourably with cytocentrifuge smears when precise quantitation of cell types is required.

The lymph node imprint technique is a useful adjunct to routine histological sectioning in the assessment of non-Hodgkin's lymphoma (NHL), allowing the pathologists to appreciate the cellular changes underlying the disease. ${ }^{1}$ Recently the technique has been used in immunocytochemical, ${ }^{2}{ }^{3}$ morphometric, ${ }^{45}$ and quantitative nuclear DNA studies ${ }^{6}$ of lymphoid tissue. The advantages of the imprint technique include ease of preparation and preservation of cellular morphology, although it is said to introduce selective bias in favour of cells which are more adhesive to a glass slide.

Few comparisons have been made between cytological and histological preparations, using morphometric techniques. We have questioned the validity of comparing two such different preparations. ${ }^{57}$ An alternative approach is to compare the imprint technique with a similar cytological method. We therefore undertook a comparative study using cytocentrifuge smears as controls. These preparations provided a standard whereby the accuracy of the imprint method could be determined. We compared cell dimensions and the distribution of cell types identified on both preparations using semi-automated image analysis.

\section{Material and methods}

Lymph node imprints and cytocentrifuge smears

Accepted for publication 25 February 1987 from 12 patients with histologically confirmed nonHodgkin's lymphoma were analysed. These cases were classified in accordance with the modified Rappaport scheme. ${ }^{8}$ They comprised three cases of diffuse well differentiated lymphocytic lymphoma, one of nodular poorly differentiated lymphocytic lymphoma, two each of nodular and diffuse mixed lymphocytic histiocytic lymphoma, three of diffuse histiocytic lymphoma and one of undifferentiated lymphoma of non-Burkitt's type.

Fresh lymphoid tissue was sent to the laboratory with minimal delay. Before fixation each lymph node was carefully cut with a sharp scalpel blade through the hilum, and lymph node imprints were made by gently touching the freshly cut surface of the node with a clean non-albuminised glass slide. Sideways movement of the slide was avoided to minimise artefactual distortion of cells. Six slides were prepared from each node by experienced cytotechnologists, and these were air dried before Jenner Giemsa stain was applied.

Before collecting tissue samples for histological, immunological, and ultrastructural studies, a representative slice of tissue - cut parallel to the imprint surface and about $5 \mathrm{~mm}$ wide-was collected into RPMI 1640 for cytocentrifuge smears. Cell suspensions were prepared by gently teasing tissue through a $1 \mathrm{~mm}$ gauge wire mesh. The cell suspension was resuspended in $30 \%$ bovine serum albumin, and cytological smears, using slides not coated in albumin, were prepared with a cytocentrifuge (Shandon Scientific Co Ltd, London). The centrifuge was spun 
at $250 \mathrm{rpm}$ for five minutes, and the preparation was air dried before Jenner Giemsa stain was applied.

\section{MOR PHOMETRIC ANALYSIS}

Random non-overlapping fields of the cell preparations were photographed. These fields were selected by using a random number table and the calibrated $x-y$ axis of the microscope stage. After the coordinates were selected the microscope stage was not adjusted until photography of that field had been completed; this was to ensure that the observer did not select cells of particular interest, which would have introduced bias into the sampling procedure.

The photographic negatives were projected by means of a Leitz projector on to a digitiser pad (HP9874A). The final magnification was adjusted to obtain an average projected cell image diameter of about 4-5 cm. The nuclear, nucleolar, and cytoplasmic contours of all cells within the field, excluding those with disrupted cell membranes, were traced. The distance between digitised points of the final projected image was set at $3 \mathrm{~mm}$, and data collection and analysis were done on a Hewlett-Packard (200 series) computer interfaced with the digitiser pad. The computer calculated the area and perimeter of each digitised contour, and statistics including mean, standard deviation, skewness, and kurtosis were derived for each cell feature. Standard deviation is an estimator of the dispersion of values within a distribution, whereas skewness is a measure of asymmetry. When most of the values lie below the mean, skewness is positive; a negative value indicates the reverse. Kurtosis indicates whether the distribution is flat (platykurtic), normal, or with a pronounced peak (leptokurtic).

In addition, the nuclear contour index (NCI) was used to quantitate nuclear shape. This index is defined as the perimeter of the nuclear outline divided by the square root of the nuclear area. This shape descriptor is independent of size and has a theoretical minimum value of $3.54 .^{9}$ On the basis of previous results using this shape index, the computer was programmed to calculate the proportion of cells with an NCI of $\geqslant 4 \cdot 2$, because these cells were characterised by irregular or cleaved nuclear profiles. Nuclei with nuclear area measurements of less than $80 \mu \mathrm{m}^{2}$, between $80-160$ $\mu \mathrm{m}^{2}$, and greater than $160 \mu \mathrm{m}^{2}$ were grouped accordingly, these cell categories were defined as small, medium, and large lymphocytes, respectively.

So that valid statistical comparisons could be made between techniques, a standardised measurement protocol to determine the optimal number of cells required for quantitation was adopted. Computer generated plots of the cumulative mean of nuclear area were derived for each case. A minimum of 150 cells were digitised, and the measurement procedure was completed when the fluctuation in the cumulative mean was within $5 \%$ over at least 50 separate cell measurements. The total number of cells traced for each case ranged from 150 to 300 cells.

Interobserver and intraobserver variability were assessed for the cell measurements under investigation. Reproducibility was excellent-within $5 \%$ - for all measurements with the exception of nucleolar area, which showed greater variability in individual measurements (less than $10 \%$ ).

\section{STATISTICAL ANALYSIS}

Comparability of the two techniques was determined by analysing the mean per cent difference between values; this measure is an estimate of systematic error or bias. ${ }^{10}$ As the cytocentrifuge technique was accepted as the standard with which to compare the imprint method, this systematic error or bias is defined as follows:

$$
\bar{X} \%=\sum_{n=1}^{n}\left(\frac{\frac{\bar{X}_{I}-\bar{X}_{C}}{\bar{X} c} \cdot \frac{100}{1}}{n}\right)
$$

where $\bar{X}_{I}, \bar{X}_{C}=$ mean value obtained on imprint and cytocentrifuge smears, respectively, and $n=$ number of cases.

A negative sign for systematic error indicates that, on average, a lower mean value for a measurement was derived using the imprint technique. The standard deviation, which reflects the random error in the measurement procedure, was also derived. The hypothesis of zero bias was examined by Student's $t$ test, and the level of significance set at $5 \%$.

\section{Results}

Tables 1 and 2 summarise the results of the comparison between the imprint and cytocentrifuge techniques. The figure shows a schematic representation of the data.

There were no significant differences in the mean nuclear area measurements between imprint and cytocentrifuge preparation; there was, however, a slight tendency towards higher mean values using the imprint technique (table 1). The shape of the distribution curve described by standard deviation, skewness, and kurtosis for this and the other cell features studied was of interest.

The standard deviation of nuclear area, obtained on imprints, was consistently lower compared with that using cytocentrifuge smears, suggesting a less dispersed cell population; the systematic error or bias of the measurement was significant $(p<0.05)$. Nuclear area measurements were further characterised on imprints by a distribution that was more positively 
Table 1 Comparison of imprint and cytocentrifuge techniques

\begin{tabular}{|c|c|c|}
\hline & $\begin{array}{l}\text { Mean \% difference } \\
\text { (systematic error } \\
\text { or bias) }\end{array}$ & $\begin{array}{l}\text { Standard deviation } \\
\text { (random error) }\end{array}$ \\
\hline $\begin{array}{l}\text { Nuclear area }\left(\mu \mathrm{m}^{2}\right) \\
\text { Mean } \\
\text { Standard deviation } \\
\text { Skewness } \\
\text { Kurtosis }\end{array}$ & $\begin{array}{l}1.5(\mathrm{NS}) \\
-\quad 14.0(\mathrm{p}<0.05) \\
19.3(\mathrm{NS}) \\
98.2(\mathrm{NS})\end{array}$ & $\begin{array}{r}8.8 \\
21.3 \\
391.9 \\
3523.7\end{array}$ \\
\hline $\begin{array}{l}\text { Nuclear shape (NCI) } \\
\text { Mean } \\
\text { Standard deviation } \\
\text { Skewness } \\
\text { Kurtosis }\end{array}$ & $\begin{array}{r}2.3(\mathrm{p}<0.01) \\
-\quad 26.6(\mathrm{p}<0.01) \\
44.4(\mathrm{p}<0.01) \\
409.8(\mathrm{NS})\end{array}$ & $\begin{array}{r}2 \cdot 5 \\
27 \cdot 1 \\
98 \cdot 8 \\
100 \cdot 8\end{array}$ \\
\hline $\begin{array}{l}\text { Nucleolar area }\left(\mu^{2}\right) \\
\text { Mean } \\
\text { Standard deviation } \\
\text { Skewness } \\
\text { Kurtosis }\end{array}$ & $\begin{array}{l}16 \cdot 3 \cdot(\mathrm{p}<0.05) \\
32 \cdot 7(\mathrm{NS}) \\
58.0(\mathrm{NS}) \\
190.7(\mathrm{NS})\end{array}$ & $\begin{array}{r}22 \cdot 9 \\
60 \cdot 4 \\
112 \cdot 2 \\
378 \cdot 3\end{array}$ \\
\hline $\begin{array}{l}\text { Cytoplasmic area ( } \mu m \\
\text { Mean } \\
\text { Standard deviation } \\
\text { Skewness } \\
\text { Kurtosis }\end{array}$ & $\begin{array}{l}3.3(\mathrm{NS}) \\
-\quad 30.9(\mathrm{p}<0.05) \\
39.6(\mathrm{NS}) \\
208.1(\mathrm{NS})\end{array}$ & $\begin{array}{r}8.6 \\
25 \cdot 6 \\
117 \cdot 6 \\
1372 \cdot 1\end{array}$ \\
\hline
\end{tabular}

skewed with a tendency towards fewer numbers of large cells, and which showed a more pronounced peak compared with that of the cytocentrifuge preparation. None of these trends, however, was significant.

The random error for nuclear area, skewness, and kurtosis was high, suggesting the presence of uncontrollable variables in the preparation of imprint smears. Likewise, high random errors were derived for skewness and kurtosis of nuclear shape, nucleolar, and cytoplasmic areas.

Table 2 shows the proportion of cells within small, medium, and large nuclear size categories. It must be emphasised that these values represent the percentage of cells, and that estimates of error were not for absolute measurements, as depicted in table 1. Although there was no significant difference in the mean proportion of cells, a negative bias in the measurement suggests a tendency towards fewer lymphocytes within each of these size categories on the imprint smears.

The nuclear shape data presented in table 1 show a significant difference in values obtained for mean,
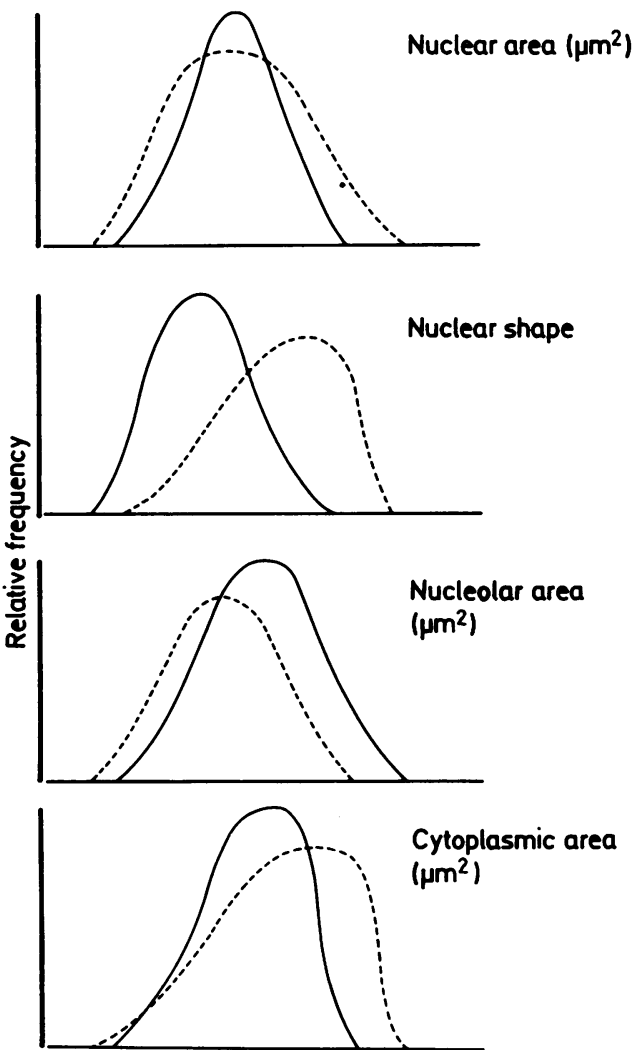

Figure Schematic representation of distribution of cell features for imprint (—) and cytocentrifuge (......) preparations.

standard deviation, and skewness. The NCI records a lower mean value on the imprint smear; moreover, the distribution of this measurement was less dispersed and more positively skewed in favour of nuclei, with less irregular configurations. These findings, which indicate a more homogeneous cell population with regard to nuclear shape, were further supported by the values derived for kurtosis; the value obtained did not differ significantly between techniques, but there was a tendency for the distribution of nuclear shape to express a more pronounced peak. An appreciation of nuclear shape on the cyto-

Table 2 Proportion of cell types on imprint and cytocentrifuge smears

\begin{tabular}{lllll}
\hline & \multicolumn{2}{l}{ Nuclear area } & & $\begin{array}{l}\text { Nuclear shape } \\
\text { NCI }\end{array}$ \\
\cline { 2 - 4 } & $<80 \mu \mathrm{m}^{2}$ & $80-160 \mu \mathrm{m}^{2}$ & $>160 \mu \mathrm{m}^{2}$ & $-36 \cdot 4$ \\
\hline Mean \% difference (systematic error or bias) & $-\mathrm{NS}^{3 \cdot 8}$ & $\mathrm{NS}^{3 \cdot 3}$ & $\mathrm{NS}$ & $\mathrm{p}<0.05$ \\
Standard deviation (random error) & 24.3 & 38.4 & 37.9 & $54 \cdot 4$ \\
\hline
\end{tabular}


centrifuge smears was further substantiated by the findings shown in table 2; the difference in the proportion of cells with an NCI of $\geqslant 4.2$ was significant at the $5 \%$ level.

The mean nucleolar area was not directly comparable using either technique ( $p<0.05)$, and this may be related in part to the poor reproducibility associated with digitising this feature. The statistics defining the distribution of nucleolar area on imprint smears show trends which suggest populations with an increased standard deviation, a spread in favour of larger nucleoli, and a distribution characterised by a more pronounced peak. These differences were not significant. Although there was no significant difference in mean cytoplasmic area, there was a tendency towards lower values on the imprint smear; cytoplasmic cell borders were more readily identified on cytocentrifuge preparations. A significant difference in the standard deviation of cytoplasmic area was noted $(\mathrm{p}<0.05)$, with a greater range of measurements recorded on the cytocentrifuge preparations. Moreover, the shape of the distributions, as defined by skewness or kurtosis, were similar to those derived for nuclear area measurements.

\section{Discussion}

An unexpected finding in this study was the similar mean nuclear area values obtained with both techniques. During the preparation of cytocentrifuge smears, cells are subjected to a centrifugal force, and subsequent flattening of cells on to the glass slide would be expected to result in increased nuclear area measurements. For both techniques, slides not coated with albumin were used because, according to Gill, ${ }^{11}$ a thin film of albumin between the cell and slide surface prevents cells from flattening adequately during cytological preparation. We found it necessary, however, to resuspend cell suspensions in $30 \%$ albumin to minimise cell disruption during cytocentrifugation, and this could have accounted for the similarity in mean nuclear area measurements.

The slight tendency for cells to flatten more on imprint smears would also explain in part the higher mean nucleolar area, increased range in nucleolar measurements, and the skewed distributions in favour of larger nucleoli, evident with this technique.

Analysis of the distribution of nuclei indicates that the imprint technique underestimates the number of large lymphoid cells. Likewise, fewer small lymphocytes were identified on the imprint smear, although this difference was not significant. Certain cell types, therefore, were not present on imprint smears. The greater range of cell types present on the cytocentrifuge smear further substantiates that the imprint technique introduces selective bias in favour of certain cell types.

The degree of irregularity of the nuclear contour was more easily appreciated on cytocentrifuge preparations. The influence of centrifugal forces on cells tends to accentuate subtle variations in nuclear shape, and as a result, nuclear invaginations are more easily discerned. The presence of artefactual distortion of cells during centrifugation cannot be discounted; this may, however, be minimised by preparing smears at a low centrifugation speed. In addition, adoption of a standardised technique ensures that any artefactual distortion introduced is applied consistently in the preparation of specimens.

A further disadvantage of the imprint technique is the poor preservation and identification of the cytoplasmic border. This may be related to the unavoidable shearing forces present during imprinting that result in disruption of the fragile thin rim of cytoplasm.

A distinctive feature of the data was the unacceptable random error obtained for most of the statistics analysed, especially skewness and kurtosis. This suggests that uncontrollable variables are present in the imprint procedure. Further studies arc needed to determine the influence of such factors as the variation in the pressure applied during imprinting, the possible effects of different rates of air drying of cells, compared with the albumin coated cells in the cytocentrifuge technique, and the variations between observers in the technical preparation of smears.

An underlying assumption in this study is that the cytocentrifuge technique is the standard cytological method with which to compare imprint smears. Nevertheless, the cytocentrifuge technique has been criticised for several reasons. Barrett et $a^{12}$ evaluated various cytopreparatory methods and concluded that recovery and preservation of cells were unpredictable using the technique. In a subsequent study of specimens of cerebrospinal fluid ${ }^{13}$ cell counts obtained by the cytocentrifuge method were found to be comparable with those obtained by a standard haemocytometer: improved cellular morphology was also noted. Observance of correct cytological technique in the preparation of smears is essential to minimise any cell loss or distortion. ${ }^{11}$ Only from the examination of optimal cytological preparations can inferences regarding the cellular composition of a tissue sample be made more accurately.

Although the imprint technique has a role in the appreciation of cellular morphology, the results of this study suggest that the technique is less suitable for quantitative investigations. Though the technique is not as rapid as the imprint procedure, cytocentrifuge smears can be simply obtained within a reasonable length of time. More importantly, it is eas- 
ily standardised, thus contributing to the attainment of optimal cell preparations.

We thank Ms B Hamden for secretarial help and $\mathrm{Mr}$ $M$ Hullan for preparing the illustration.

\section{References}

1 Ultmann JE, Koprowska I, Engle RL. A cytological study of lymph node imprints. Cancer 1958;11:507-24.

2 Banks PM, Caron BL, Morgan TW. Use of imprints for monoclonal antibody studies: suitability of air dried preparations from lymphoid tissues with an immunochistochemical method. Am J Clin Pathol 1983;79:438-42.

3 Giorno R. Characterisation of mononuclear cells in cytocentrifuge and imprint preparations using monoclonal antibodies and an avidin-biotin immunoperoxidase staining system. J Histochem Cytochem 1983;32:1326-8.

4 Crocker J, Curran RC. A study of nuclear diameters in lymph node imprints using the Zeiss microvideomat. J Clin Pathol 1979;32:670-4.

5 Ball PJ, Van Der Valk P, Kurver PHJ, Lindeman J, Meijer CJLM. Large cell lymphoma II. Differential diagnosis of centroblastic and B-immunoblastic subtypes by morphometry on cytologic preparations. Cancer 1985;55:486-92.

6 Van Vloten WA, Scheffer E, Meijer CJLM. DNA- cytophotometry of lymph node imprints from patients with mycosis fungoides. J Invest Dermatol 1979;73:275-7.

7 Felman P, Bryon PA, Gentilhomme O, et al. Burkitt's lymphoma. Distinction of subgroups by morphometric analysis of the characteristics of 55 cell lines. Anal Quant Cytol Histol 1985;7:275-82.

8 Rappaport H. Tumours of the hemopoietic system. In: Atlas of tumour pathology, section 3, Fascicle 8. Washington, DC: US Armed Forces Institute of Pathology, 1966: 91-206.

9 Schrek R. Ultrastructure of blood lymphocytes from chronic lymphocytic and lymphosarcoma cell leukemia. JNCI 1972;48:51-64.

10 Altman DG, Bland JM. Measurement in medicine: the analysis of method comparison studies. Statistician 1983;32:307-17.

11 Gill GW. The Shandon Cytospin 2 in diagnostic cytology: techniques, tips, and troubleshooting. Cytospin 2 technical manual. 1982: 21-2.

12 Barrett DL, King EB. Comparison of cellular recovery rates and morphologic detail obtained using membrane filter and cytocentrifuge techniques. Acta Cytol 1976;20:174-80.

13 Whitmore EL, Hochberg F, Wolfson L, Royalty J, Taft PD. Quantitative cytocentrifugation in the evaluation of cerebrospinal fluid. Acta Cytol 1982;26:847-50.

Requests for reprints to: Mr MW Stevens, Division of Tissue Pathology, Institute of Medical and Veterinary Science, PO Box 14, Rundle Street, Adelaide, South Australia 5000. 